\title{
Covid-19: A wake-up call
}

\author{
Fiona Godlee editor in chief
}

The BMJ

There will be things that the UK government has got right in managing the covid pandemic, but at this point in the proceedings it is hard to identify what those are. Some readers have questioned whether The BMJ's bleak assessment (doi:10. $1136 / \mathrm{bmj} . \mathrm{m} 1918$ ) is justified and asked us to be more supportive (https://bit.ly/3g6DG43). Few can doubt the size of the government's challenge or the good faith and expertise of its chief advisers. But if ministers won't share the thinking and evidence behind their decisions, we can only judge them on the results. They are in power, and we and others must hold them to account.

"Too little, too late, too flawed" is the verdict of our editorialists (doi:10.1136/bmj.m1932), as they ask, "How did a country with an international reputation for public health get it so wrong?" Their answer is a sad litany of past and present decisions that have fragmented, decimated, and marginalised public health in the run up to this moment when it is most needed. Their overriding message is that clear leadership from the centre needs to be matched with strong operational capacity at the local level. The UK currently has neither.

This has been most dismally demonstrated by the continuing failure to establish a coherent system for community based case finding and contact tracing, without which there can be no safe exit from lockdown. This should be low tech and locally driven, with trained staff and volunteers providing boots on the ground, as employed to good effect in Africa during the Ebola outbreaks (https://bit.ly/36ixtgJ). Massachusetts and France are two high resource settings that have chosen this approach. It is ironic that the UK promoted and supported the approach in Africa but seems either unwilling or unable to adopt it at home. The government is now recruiting thousands of contact tracers, but at the time of writing it remains dangerously enamoured of its as yet unproved contact tracing app (doi:10.1136/bmj.m1859, doi:10.1136/bmj.m1818).

As well as exposing the erosion of England's public health system (doi:10.1136/bmj.m1934), covid could lead us to do things we have long known needed doing: advance care planning as a routine (doi:10.1136/bmj.m1927), more thoughtful decisions on use of resources (doi:10.1136/bmj.m1979), not wasting research effort (doi:10.1136/bmj.m1847), greater openness about the evidence behind decisions (doi:10.1136/bmj.m2000; doi:10. $1136 / \mathrm{bmj} . \mathrm{m} 2022$ ), legislation to reduce the effect of alcohol on health and society (doi:10.1136/bmj.m1987), prioritising the care of elderly and vulnerable people (doi:10.1136/bmj.m1858; doi:10.1136/bmj.m1629), reversing the historical neglect of social care (doi:10.1136/bmj.m1937), putting our shoulders to the wheel of tackling climate change (https://bit.ly/3e $4 \mathrm{eJVc}$ ), and properly looking after healthcare workers so that they can look after us (https://bit.ly/36f6Mtu; doi:10.1136/bmj.m1815).

Is this, then, the wake-up call we have needed to plan a new future? Yes, writes Ali Mehdi (doi:10.1136/bmj.m1919), in the same way as did the planners of the welfare state during the second world war. Others agree. After describing how covid-19 disproportionately affects the poorest people in our society, Adam Briggs and Harry Rutter say the pandemic can't become an excuse for worsening population health and widening inequalities (https://bit.ly/3e4PXnS). Instead we must seize this crisis as an opportunity to build a healthier and more equal society. 